\title{
Global climate strike
}

\author{
The global average temperature has been continuously rising for over a century. Action must be taken.
}

( uring 20-27 September various groups of climate activists worldwide organized multiple strikes and protests around the United Nations Climate Action Summit, held in New York on 23 September, to demand stronger action on climate change, in what was called the Global Week for Future. According to the organizers, more than 4 million people from 185 countries joined the climate strike day on 20 September. Ambitious goals include fully divesting from fossil fuels by 2020 and transitioning to $100 \%$ renewable energy by 2030 .

Anthropogenic global warming is a devastating consequence of the increased atmospheric concentration of greenhouse gases - mostly carbon dioxide and methane - due to human activity. The Paris Agreement, signed by 195 states in 2016, aims to hold the increase in global average temperature at no more than $2{ }^{\circ} \mathrm{C}$ above pre-industrial levels while pursuing efforts to limit it to $1.5^{\circ} \mathrm{C}$. However, the Intergovernmental Panel on Climate Change warned that reaching the $1.5^{\circ} \mathrm{C}$ goal would encompass massive efforts, with an estimated annual cost of US $\$ 2.4$ trillion, necessitating a $50 \%$ reduction of greenhouse gas emissions by $2030^{1}$.

Catalysis is destined to play an important role in the quest to mitigate global warming. Catalysts are crucial for the production of clean fuels such as hydrogen. Current hydrogen production mostly relies on catalytic methane or natural gas steam reforming, combined with the water-gas shift reaction. However, carbon dioxide is an unavoidable by-product - as it is for other non-catalytic hydrogen production processes such as coal or biomass gasification. Cleaner technologies are being developed, such as dry reforming or (photo)electrochemical water splitting, which also involve the use of catalysts. The latter process is especially relevant for the climate when powered with electricity from renewable sources like solar panels or wind turbines.

\section{"Catalysis is destined to play an important role in the quest to mitigate global warming."}

Hydrogen is used as a fuel to produce electricity in hydrogen fuel cells, where both anodic and cathodic reactions require catalysts. Hydrogen vehicles are already a reality and their market share is expected to grow fast. Indeed, transportation accounts for $20 \%$ of total carbon dioxide emissions worldwide $^{2}-29 \%$ of emissions in the United States $^{3}$ and $27 \%$ in the 28 European Union member states, with road transport alone representing more than $70 \%$ of this number in Europe ${ }^{4}$. Nature Catalysis recently published an Insight devoted to the impact of catalysis in the transportation sector, covering topics relevant to climate change such as fuel cells or emissions control. Fuel cells that use fuels other than hydrogen are also being investigated, such as direct methanol or direct formic acid fuel cells, but they produce carbon dioxide and are thus less effective to fight global warming unless the fuel is obtained from carbon dioxide and the overall process becomes carbon neutral. Electric vehicles that use batteries are naturally very interesting for such a purpose and at a more mature stage than those based on fuel cells, although they currently do not rely on catalytic batteries.

Another front where catalysis research will surely contribute to the mitigation of climate change is through carbon dioxide utilization. Carbon dioxide can be recycled to produce a variety of value-added products, such as methanol, formic acid, ethylene, ethanol or propanol, which can be used as fuels or chemical feedstocks. This has a double effect, since on the one hand it decreases (or prevents increasing) carbon dioxide atmospheric levels, and on the other it allows the production of chemicals that would otherwise be obtained via carbonintensive processes such as cracking. Similar considerations should be made for industrial processes that demand large amounts of energy. One such example is the HaberBosch process, which itself is responsible for $1.4 \%$ of global carbon dioxide emissions ${ }^{5}$. Replacing energy- and carbon-intensive processes with cleaner alternatives will be a major step to decrease our global carbon footprint. Nevertheless, every time a new approach is suggested, one should look at the whole process lifecycle (or system approach) in order to determine if the new solution achieves real net carbon dioxide reduction ${ }^{6}$.

The effects of climate change are already perceptible. Loss of sea ice, glaciers melting, rise of sea level, record-high temperatures, and droughts are just some of the consequences that are already happening worldwide. We must take action and work together to stop and reverse the current trends. We must unite behind the science.

Published online: 11 October 2019 https://doi.org/10.1038/s41929-019-0374-8

References

1. Nature 573, 309 (2019).

2. CO2 Emissions from Transport (\% of Total Fuel Combustion) (World Bank, 2014); https://go.nature.com/2mhBijI

3. Sources of Greenhouse Gas Emissions (United States Environmental Protection Agency, 2017); https://go.nature. com/2merYNF

4. Transport Emissions (European Commission, 2016); https:// go.nature.com/21DiE5K

5. Soloveichik, G. Nat. Catal. 2, 377-380 (2019).

6. Tackett, B. M., Gomez, E. \& Chen, J. G. Nat. Catal. 2, 381-386 (2019) 